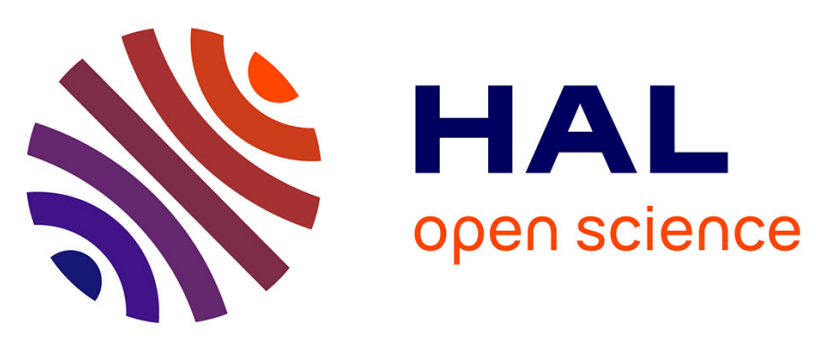

\title{
Biochemical characterization and mutational studies of the 8-oxoguanine DNA glycosylase from the hyperthermophilic and radioresistant archaeon Thermococcus gammatolerans
}

Likui Zhang, Yuting Li, Haoqiang Shi, Dai Zhang, Zhihui Yang, P. Oger, Jianting Zheng

\section{To cite this version:}

Likui Zhang, Yuting Li, Haoqiang Shi, Dai Zhang, Zhihui Yang, et al.. Biochemical characterization and mutational studies of the 8-oxoguanine DNA glycosylase from the hyperthermophilic and radioresistant archaeon Thermococcus gammatolerans. Applied Microbiology and Biotechnology, 2019, 10.1007/s00253-019-10031-w . hal-02283293

\section{HAL Id: hal-02283293 \\ https://hal.science/hal-02283293}

Submitted on 17 Jun 2020

HAL is a multi-disciplinary open access archive for the deposit and dissemination of scientific research documents, whether they are published or not. The documents may come from teaching and research institutions in France or abroad, or from public or private research centers.
L'archive ouverte pluridisciplinaire HAL, est destinée au dépôt et à la diffusion de documents scientifiques de niveau recherche, publiés ou non, émanant des établissements d'enseignement et de recherche français ou étrangers, des laboratoires publics ou privés. 
Biochemical characterization and mutational studies of the 8-oxoguanine DNA glycosylase from the hyperthermophilic and radioresistant archaeon

\section{Thermococcus gammatolerans}

Likui Zhang ${ }^{\mathrm{a}^{* \#}}$, Yuting $\mathrm{Li}^{\mathrm{a}^{*}}$, Haoqiang Shi ${ }^{\mathrm{a}^{*}}$, Dai Zhang ${ }^{\mathrm{b}}$, Zhihui Yang ${ }^{\mathrm{b}}$, Philippe Oger $^{\mathrm{ct}}$ and Jianting Zheng ${ }^{\mathrm{d}}$

${ }^{a}$ Marine Science \& Technology Institute

Department of Environmental Science and Engineering, Yangzhou University, China

${ }^{\mathrm{b} C o l l e g e}$ of Plant Protection, Agricultural University of Hebei, Baoding City, Hebei Province 071001, China

'Univ Lyon, INSA de Lyon, CNRS UMR 5240, Villeurbanne, France

${ }^{\mathrm{d} S t a t e}$ Key Laboratory of Microbial Metabolism, School of Life Sciences and Biotechnology, Shanghai Jiao Tong University, Shanghai 200240, China.

${ }^{*}$ These authors contributed equally to this work.

Corresponding author: Dr. Likui Zhang

Tel: +86-514-89795882

Fax: $+86-514-87357891$

E-mail address: 1kzhang@yzu.edu.cn

Corresponding author: Prof. Zhihui Yang

E-mail address: bdyzh@hebau.edu.cn

Corresponding author: Prof. Philippe Oger

E-mail address: philippe.oger@insa-lyon.fr 


\begin{abstract}
8-oxoguanine $(\mathrm{GO})$ is a major lesion found in DNA that arises from guanine oxidation. The hyperthermophilic and radioresistant euryarchaeon Thermococcus gammatolerans encodes an archaeal GO DNA glycosylase (Tg-AGOG). Here, we characterized biochemically $\mathrm{Tg}$-AGOG and probed its GO removal mechanism by mutational studies. $\mathrm{Tg}$-AGOG can remove GO from DNA at high temperature through a $\beta$-elimination reaction. The enzyme displays an optimal temperature, ca. $85^{\circ} \mathrm{C}$, and an optimal $\mathrm{pH}$, ca.7.0-8.5. In addition, $\mathrm{Tg}$-AGOG activity is independent on a divalent metal ion. However, both $\mathrm{Co}^{2+}$ and $\mathrm{Cu}^{2+}$ inhibit its activity. The enzyme activity is also inhibited by $\mathrm{NaCl}$. Furthermore, $\mathrm{Tg}$-AGOG specifically cleaves GOcontaining dsDNA in the order: GO:C, GO:T, GO:A and GO:G. In comparison with the wild-type $\mathrm{Tg}$-AGOG, the R197A mutant has a reduced cleavage activity for GOcontaining DNA, whereas both the P193A and F167A mutants exhibit similar cleavage activities for GO-containing DNA. While the mutations of P193 and F167 to Ala lead to increased binding, the mutation of R197 to Ala had no significant effect on binding. These observations suggest that residue R197 is involved in catalysis, and residues P193 and F167 are flexible for conformational change.
\end{abstract}

Keywords: 8oxoG-DNA glycosylase; Base excision repair; Thermococcus gammatolerans 


\section{Introduction}

Oxidative damage to DNA is under constant threat from reactive oxygen species (ROS) for the genomic integrity of an organism, potentially leading to a wide range of diseases, including atherosclerosis, strokes, autoimmune syndromes and Alzheimer's disease (Harman 1992; Sliwinska et al. 2016). Among various types of ROS generated lesions, 8-oxoguanine (GO) is the most well-characterized lesion in DNA (Grollman AP and Moriya M 1993). As estimated, approximately 100,000 GO lesions in DNA are created per day in an average mammalian cell (Park et al. 1992). GO can adopt two conformations: one is the anti-conformation, which allows GO to form a Watson-Crick pair with cytosine (GO:C), and the other is the synconformation, which enables GO to form a stable Hoogsteen pair with adenine (GO:A) (Shibutani et al. 1991; Kuchino et al. 1987). Thus, GO in the DNA template during replication would induce a G:C $\rightarrow$ T:A transversion (Pearson et al. 2004). On the other hand, 8-oxo-dGTP can be incorporated opposite the template base dA by a DNA polymerase, thus leading to an A:T $\rightarrow$ C:G transversion (Shimizu et al. 2003). In response, cells have evolved several mechanisms to repair this oxidative damage in DNA, one of which is known as the base excision repair (BER) pathway (McCullough et al. 1999; Seeberg et al. 1995). BER is initiated by a GO DNA glycosylase that is ubiquitous in all organisms (Hazra et al. 2001), which cleave the $\mathrm{N}$-glycosidic bond between the aberrant base and the sugar-phosphate backbone to generate an apurinic (AP) site.

The GO DNA glycosylases responsible for GO removal are called formamidopyrimidine-DNA glycosylase (Fpg) and 8-oxoguanine DNA glycosylase (OGG). While Fpg is found mostly in bacteria, OGG is present in eukaryotes, archaea, and a few bacteria.

The OGGs belong to the HhH-GPD superfamily, possessing a helix-hairpin-helix $(\mathrm{HhH})$ signature motif (Nash et al. 1996; Thayer et al. 1995), and their members are divided into three families: OGG1, OGG2 and archaeal GO glycosylase (AGOG). Although a few bacteria harbor OGG1 enzymes, the OGG1s are found essentially in 
eukaryotes. The OGG1 family contains the largest number of members, including the well-studied human OGG1 (hOGG1) (Shinmura et al. 1997), however, they vary considerably in size. The structure of OGG1 show that these enzymes exhibit a similar tertiary fold composed of three domains (Faucher et al. 2009b; Lingaraju et al. 2005). OGG2 family incudes primarily archaeal enzymes, such as Methanocaldococcus janischii OGG and Sulfolobulus solfataricus OGG (Faucher et al. 2010; Faucher et al. 2009a). The structures of the two archaeal OGG2s comprise two domains separated by the $\mathrm{HhH}$ motif. In contrast to OGG1, OGG2 is less variable in size ( \pm 207 amino acids) (Faucher et al. 2009a; Gogos and Clarke 1999; Im et al. 2005), and also displays a less stringent opposite base specificity than OGG1 (Gogos and Clarke 1999; Im et al. 2005). Last, members of the third family, AGOG, which is exclusively found in archaea, share a similar two-domain architecture with OGG2. However, the HhH motif in AGOG is distinct from that of OGG1 or OGG2 (Nash et al. 1996; Thayer et al. 1995).

The alignment of amino acid sequences suggest that OGG members exhibit very low sequence homology, except for possessing conserved helix-hairpin-helix motif. For example, OGG2 members share only $13-19 \%$ sequence identity with OGG1. Even members of OGG1 can exhibit very low sequence homology with one another: the bacterial OGG1 from Clostridium acetobutylicum shares only 28\% identity with its human counterpart (hOGG1) (Faucher et al. 2009b). Although they contain similar HhH motif, OGG1, OGG2 and AGOG subfamilies have considerably distinct threedimensional fold. For example, OGG2 members lack the A-domain in OGG1 which is involved in GO binding (Faucher et al. 2012). Furthermore, all three OGG subfamilies have different manners to bind GO even though the crucial interaction between the enzyme and the protonated N7 of GO is conserved (Faucher et al. 2012). Thus, the three OGG subfamilies vary with respect to DNA binding properties and cleavage mechanism.

Since the first GO DNA glycosylase was identified from M. jannaschii (Gogos and Clarke 1999), five GO DNA glycosylases from archaea have been characterized 
biochemically or structurally: Archaeoglobus fulgidus (Chung et al. 2001), S. solfataricus (Faucher et al. 2009a), Pyrobaculum aerophilum (Lingaraju et al. 2005; Sartori et al. 2004; Lingaraju et al. 2009), Thermococcus gammatolerans (Barbier et al. 2016), and Thermoplasma volcanium (Fujii et al. 2016). The crystal structure of $\mathrm{Pa}$-AGOG in apo-form shows that it is the member of the HhH-GPD superfamily, possessing a conserved HhH-GPD motif (Sartori et al. 2004). However, the conserved HhH-GPD motif of $\mathrm{Pa}$-AGOG is clearly distinct from hOGG1 and other members of the HhH-GPD superfamily (Lingaraju et al. 2005). Despite the location and shape of the GO recognition pocket similar to those observed in hOGG1, $P a$-AGOG $(P$. aerophilum AGOG) has an unique pattern for GO-recognition. The structure of the $\mathrm{Pa}$-AGOG-GO-nucleoside complex provides insight into GO recognition and removal mechanism. The aromatic rings of residues F144 and W222 of Pa-AGOG enables the GO-nucleoside to be stacked. Residues N31 and D218 in Pa-AGOG play important roles in GO recognition (Sartori et al. 2004). Contrast to hOGG1, which recognizes the protonated N7 of GO through a main chain carbonyl, $P a$-AGOG recognizes the same position through the carbonyl group of the N31 side chain (Lingaraju et al. 2005; Bruner et al. 2000; Fromme and Verdine 2003). Furthermore, Pa-AGOG contacts GO via a direct hydrogen bond donated by W69, which differs from hOGG1 (Radom et al. 2007). Residues D172 and K140, which are situated at the conserved positions within the HhH-GPD motif, are proved to be catalytic residues (Lingaraju et al. 2009). Therefore, AGOGs have distinct structures from other OGGs, suggesting that their biochemical functions vary.

T. gammatolerans, a hyperthermophilic archaeon with an optimal growth temperature of $88^{\circ} \mathrm{C}$, was isolated from samples obtained in a hydrothermal vent located in the Gulf of California (Jolivet et al. 2003). This archaeon is thought as the most radioresistant archaeon to date, fully withstanding a $5.0 \mathrm{kGy}$ dose of gamma irradiation without loss of viability (Zivanovic et al. 2009). The genome of $T$. gammatolerans encodes an archaeal GO glycosylase (Tg-AGOG) (Zivanovic et al. 2009). This glycosylase is capable of removing GO from DNA at high temperature 
(Barbier et al. 2016). However, the biochemical characterization and GO removal mechanism of $\mathrm{Tg}$-AGOG remain poorly understood. In the present study, we cloned the $\mathrm{Tg}$-AGOG gene, purified and characterized its product biochemcially. We also probed the function of some residues of the enzyme through the structure-based mutagenesis studies.

\section{Materials and methods}

\section{Cloning, expression and purification of $\mathrm{Tg}$-AGOG}

The genome of T. gammatolerans encodes a TGAM_RS08370 gene of GO-DNA glycosylase (GenBank accession number: ACS34155.1). The genomic DNA of $T$. gammatolerans was provided by Prof. Fabrice Confalonieri. Using the genomic DNA as a template, the TGAM_RS08370 gene was amplified with the Phusion DNA polymerase (Thermo Scientific, Waltham, MA, USA) in the presence of the two primers containing NdeI and NotI restriction sites (Tg-AGOG F and Tg-AGOG R, Table 1). The PCR program was run by DNA denaturation at $95^{\circ} \mathrm{C}$ for 2 min followed by 30 cycles of $95^{\circ} \mathrm{C}$ for $10 \mathrm{~s}, 55^{\circ} \mathrm{C}$ for $20 \mathrm{~s}$ and $72^{\circ} \mathrm{C}$ for $30 \mathrm{~s}$, with a final extension step at $72^{\circ} \mathrm{C}$ for $5 \mathrm{~min}$. The amplified DNA product was inserted into the vector $\mathrm{pET}$ 30a (+) (Novagen, Merck, Darmstadt, Germany). The recombinant plasmid harboring a sequence encoded a $6 \mathrm{x}$ His-tag at the C-terminus of $\mathrm{Tg}$-AGOG was sequenced to verify the accuracy of the sequence of the enzyme gene and then transformed into $E$. coli BL21 (DE3) cells (Transgene, Beijing, China) for protein expression.

The expression strain E. coli harboring the recombinant plasmid was cultured into LB medium with $100 \mu \mathrm{g} / \mathrm{mL}$ kanamycin at $37^{\circ} \mathrm{C}$ until an $\mathrm{OD}_{600}$ of 0.6 , at which point protein expression was induced with isopropyl thiogalactoside (IPTG) at a final concentration of $0.05 \mathrm{mM}$. The culture was further shaken for 10 hours at room temperature until it reached an $\mathrm{OD}_{600}$ of 1.1 .

The cells were harvested by centrifugation $(5,000 \mathrm{~g}$ for $20 \mathrm{~min}$ at room temperature). The pellet was resuspended in Ni column buffer A (20 mM Tris- $\mathrm{HCl}$ pH 8.0, $1 \mathrm{mM}$ dithiothreitol (DTT), $500 \mathrm{mM} \mathrm{NaCl}, 50 \mathrm{mM}$ imidazole and $10 \%$

glycerol). The cells were disrupted by sonication on ice. After centrifugation $(16,000$ 
$\mathrm{g}$ for $30 \mathrm{~min}$ at $4^{\circ} \mathrm{C}$ ), the supernatant was collected into a $50 \mathrm{~mL}$ tube and heated at $70^{\circ} \mathrm{C}$ for $20 \mathrm{~min}$. Non-thermostable E. coli proteins were removed by centrifugation at $16,000 \mathrm{~g}$ for $30 \mathrm{~min}$ at $4^{\circ} \mathrm{C}$. The resulting supernatant was loaded onto a HisTrap FF column (GE Healthcare, Uppsala, Sweden) and purified with $\mathrm{NCG}^{\mathrm{TM}}$ Chromatography System (Bio-Rad, Hercules, CA, USA). A linear gradient of 50-500 $\mathrm{mM}$ imidazole was used to elute the $\mathrm{Tg}$-AGOG protein. Fractions of the $\mathrm{Tg}$-AGOG protein were harvested and run in a 10\% sodium dodecyl sulfate-polyacrylamide gel. The Tg-AGOG protein was stained and visualized by Coomassie blue. Last, the purified $T g$-AGOG protein was dialyzed in a storage buffer containing $50 \mathrm{mM}$ Tris$\mathrm{HCl} \mathrm{pH} 8.0,50 \mathrm{mM} \mathrm{NaCl}, 1 \mathrm{mM}$ DTT and $50 \%$ glycerol, and stored at $-80^{\circ} \mathrm{C}$. The protein concentration was measured by the Bradford Protein Assay Kit (Bio-Rad), following the manufacturer's instructions.

\section{Construction, overexpression and purification of $\mathrm{Tg}$-AGOG mutants}

The Tg-AGOG F167A, P193A and R197A mutants were engineered by sitedirected mutagenesis using a Site-directed Mutagenesis Kit (Transgene, China). The mutagenesis reactions were performed using the wild-type plasmid harboring the $T g$ AGOG gene as a template, according to the manufacturer's instructions. The sequences of the mutagenic primers are summarized in Table 1. The mutant plasmids containing the desired mutations were verified by sequencing. The Tg-AGOG mutant proteins were overexpressed, purified and quantified, as described above for the wildtype protein.

\section{DNA substrates}

Normal and GO-, AP- and uracil-containing oligonucleotides were synthesized by Sangon Biotech company, China. The sequences of these oligonucleotides are shown in Table 1. The oligonucleotides (p26, p24, p22, p45G, p45GO, p45AP and p45U) were labeled with Cy3 at the 5'-terminus (shown with asterisks). The Cy3labeled duplex oligonucleotides were prepared by annealing the Cy3-labeled oligonucleotides to the complementary oligonucleotides in buffer $(20 \mathrm{mM}$ Tris- $\mathrm{Cl} \mathrm{pH}$ 8.0 and $100 \mathrm{mM} \mathrm{NaCl})$. 


\section{Glycosylase assays}

The standard assays of $T g$-AGOG activity were carried out in reactions $(10 \mu \mathrm{L})$ containing 20 mM Tris- $\mathrm{HCl} \mathrm{pH}$ 8.0, 5 mM DTT, 8\% glycerol, $200 \mathrm{nM}$ Cy3-labeled DNA and the wild-type or mutant $T g$-AGOG enzyme with various concentrations at $85^{\circ} \mathrm{C}$ for $10 \mathrm{~min}$, unless stated otherwise. Considering the stability of duplex oligonucleotide, the glycosylase assays for cleaving GO-containing dsDNA were performed at $65^{\circ} \mathrm{C}$ for $10 \mathrm{~min}$. The reaction products were heated at $95^{\circ} \mathrm{C}$ for $5 \mathrm{~min}$ and chilled rapidly on ice for $5 \mathrm{~min}$, and then loaded onto a denaturing $15 \%$ polyacrylamide gel with $8 \mathrm{M}$ urea. After electrophoresis, the gels were scanned and Cy3-labeled DNA was visualized with a Molecular Image analyser (PharosFx System, BioRad). The ImageQuant software was used for quantitative analysis. All experiments of the glycosylase assays were replicated three times.

\section{Biochemical characterization assays}

We first determined the optimal temperature of the $\mathrm{Tg}$-AGOG activity in reactions $(10 \mu \mathrm{L})$ containing $800 \mathrm{nM}$ enzyme using $200 \mathrm{nM}$ GO-containing ssDNA as a target. The reactions were performed at $45,55,65,75,85$ and $95^{\circ} \mathrm{C}$ for $10 \mathrm{~min}$. The reactions were stopped and treated as described above.

To examine the thermostability of the enzyme, $\mathrm{Tg}$-AGOG was heated at 80,85 , 90, 95 and $100^{\circ} \mathrm{C}$ for $30 \mathrm{~min}$. The activity of the heated $\mathrm{Tg}$-AGOG protein was assayed under the same conditions.

The effect of $\mathrm{pH}$ on $\mathrm{Tg}$-AGOG activity was evaluated by examining glycosylase activity in reactions performed under $\mathrm{pHs}$ ranging from 6.5 to 9.5 . The varied $\mathrm{pHs}$ were adjusted with five different buffers (all at $20 \mathrm{mM}$ concentrations): sodium phosphate- $\mathrm{NaOH}(\mathrm{pH} 6.5$ and $\mathrm{pH}$ 7.0), Tris- $\mathrm{HCl}(\mathrm{pH} 7.5, \mathrm{pH} 8.0$ and $\mathrm{pH} 8.5)$ and Gly-NaOH (pH 9.0 and pH 9.5).

The effects of divalent metal ions on $\mathrm{Tg}$-AGOG activity were investigated by

adding of $1 \mathrm{mM}$ of $\mathrm{Mg}^{2+}, \mathrm{Mn}^{2+}, \mathrm{Ca}^{2+}, \mathrm{Zn}^{2+}, \mathrm{Co}^{2+}, \mathrm{Ni}^{2+}$ or $\mathrm{Cu}^{2+}$ (analytical purity) to the reaction mixture. To evaluate the effect of salinity on the Tg-AGOG activity, DNA 
cleavage assays were performed in the presence of various $\mathrm{NaCl}$ concentrations ranging from 50 to $1,000 \mathrm{mM}$.

\section{Substrate specificity of $\mathbf{T g}$-AGOG}

To investigate $\mathrm{Tg}$-AGOG's substrate specificity, we employed GO-containing dsDNA (GO:T, GO:C, GO:G and GO:A), uracil-containing dsDNA (U/G), mismatched dsDNA (G/T), AP-containing ssDNA and AP-containing dsDNA (AP:T, AP:C, AP:G and AP:A) as substrates to perform the glycosylase assays at $65^{\circ} \mathrm{C}$ for 10 min using $800 \mathrm{nM}$ enzyme and 200nM substrates. Samples were treated as described above.

\section{DNA-binding assays}

We employed electrophoresis mobility shift assays (EMSA) to examine whether the wild-type and mutant $T g$-AGOGs bind to GO-containing DNA in a DNA binding buffer $(10 \mu \mathrm{L})$ containing $200 \mathrm{nM} \mathrm{Cy3-labeled} \mathrm{DNA,} 20 \mathrm{mM}$ Tris-HCl pH 8.0, $5 \mathrm{mM}$ DTT, $8 \%$ glycerol and various enzyme concentrations $(250-5,000 \mathrm{nM})$. The binding assays were carried out at $25^{\circ} \mathrm{C}$ for $10 \mathrm{~min}$. Samples were electrophoresed on a $4 \%$ native polyacrylamide gel in $0.1 \mathrm{x}$ TBE (Tris-borate-EDTA) buffer. After electrophoresis, the gels were scanned and Cy3-labeled DNA was visualized with a Molecular Image analyser (Bio-Rad). ImageQuant software was used for quantitative analysis.

\section{Results}

\section{Cleavage of GO-containing DNA by $\mathrm{Tg}$-AGOG}

The genome of $T$. gammatolerans encodes an arcaheal GO DNA glycosylase ( $T g$-AGOG). We aligned the amino acid sequences of $\mathrm{Tg}$-AGOG with $\mathrm{Pa}$-AGOG (Fig. 1A), a typical AGOG that is structurally and biochemically well characterized, and found that the two AGOGs share 25\% sequence homology. Despite their low similarity, the two AGOGs possess conserved residues that are involved in GO recognition and removal.

The $T g$-AGOG gene was cloned into the pET-30a $(+)$ expression vector, and expressed in E. coli BL21(DE3). The recombinant $T g$-AGOG protein was 
successfully expressed as a $\sim 27 \mathrm{kDa}$ His-tag fusion protein at its C-terminus (Fig. 1B). By using sonication, heat treatment $\left(70^{\circ} \mathrm{C}\right.$ for $\left.20 \mathrm{~min}\right)$ and affinity chromatography with a Ni column, we purified the recombinant $\mathrm{Tg}$-AGOG protein (Fig. 1B).

Using 500nM GO-containing ssDNA or dsDNA (GO:C) as substrates to investigate $T g$-AGOG activity with $500 \mathrm{nM} T g$-AGOG at $65^{\circ} \mathrm{C}$, we showed that, as expected, $T g$-AGOG can cleave both GO-containing ssDNA and dsDNA (GO:C) (Fig. 1C). Furthermore, GO-containing ssDNA was used to determine the size of product, the cleaved product of $T g$-AGOG was 25 mer (Fig. 1D), suggesting that $T g$ AGOG has a $\beta$-elimination activity as well as a glycosylase activity as suggested previously (25). Thus, $\mathrm{Tg}$-AGOG is a bifunctional enzyme that possesses GO glycosylase and AP lyase activities.

\section{Biochemical characterization of $\mathrm{Tg}$-AGOG}

In the following experiments, we investigated the biochemical characterization of $\mathrm{Tg}$-AGOG including the optimal temperature and $\mathrm{pH}$, the thermostability, metal ion utilization, and salt adaptation.

As shown in Fig. 2A, Tg-AGOG can cleave GO-containing ssDNA with varied efficiencies at temperatures ranging from $45^{\circ} \mathrm{C}$ to $95^{\circ} \mathrm{C}$, displaying an optimal cleavage efficiency at $85^{\circ} \mathrm{C}$, which essentially corresponds to the optimal growth temperature of $T$. gammatolerans. We showed that $T g$-AGOG was highly thermostable, retaining $37 \%$ cleavage activity after a $2 \mathrm{~h}$-treatment at $95^{\circ} \mathrm{C}$ (Fig. $\left.2 \mathrm{~B}\right)$. However, the activity of $\mathrm{Tg}$-AGOG was completely abolished after heating at $100^{\circ} \mathrm{C}$ for 0.5 hour. To the best of our knowledge, $T g$-AGOG is the most thermostable glycosylase among all the reported OGG enzymes. $\mathrm{Tg}$-AGOG is active from $\mathrm{pH}=6.5$ to $\mathrm{pH}=9.5$ (Fig. 2C), with an optimum for $\mathrm{pH} 7.0-8.5$.

Although a divalent metal ion is not needed for the activities of the reported AGOGs (Gogos and Clarke 1999; Barbier et al. 2016), we also examined the effects of divalent metal ions on $\mathrm{Tg}$-AGOG activity. In the absence of a divalent ion and the presence of EDTA, $\mathrm{Tg}$-AGOG showed about $88 \%$ and $67 \%$ cleavage activity (Fig. 
2D), respectively. Furthermore, we observed similar cleavage efficiencies ( $90 \%)$ in the presence of $\mathrm{Mg}^{2+}, \mathrm{Mn}^{2+}, \mathrm{Ca}^{2+}, \mathrm{Zn}^{2+}$ and $\mathrm{Ni}^{2+}$. Thus, a divalent metal ion is not needed to add for $\mathrm{Tg}$-AGOG to cleave GO-containing DNA. However, we observed that $\mathrm{Cu}^{2+}$ and $\mathrm{Co}^{2+}$ clearly inhibited cleavage.

To uncover salinity adaptation of $\mathrm{Tg}$-AGOG, various $\mathrm{NaCl}$ concentrations (50$1,000 \mathrm{mM}$ ) were added in the DNA cleavage reactions. Compared with the control reaction without $\mathrm{NaCl}$, the activity of $\mathrm{Tg}$-AGOG was inhibited by $\mathrm{NaCl}$ with varied degrees (Fig. 2E). We observed that $50 \mathrm{mM} \mathrm{NaCl}$ reduced the $\mathrm{Tg}$-AGOG activity to be $69 \%$. Increasing $\mathrm{NaCl}$ concentrations leads to further reduction of cleavage efficiencies of $\mathrm{Tg}$-AGOG. At $400 \mathrm{mM} \mathrm{NaCl}$, the enzyme only retained about $26 \%$ activity. Furthermore, the enzyme displayed about $\sim 10 \%$ cleavage efficiencies in the presence of at $800 \sim 1,000 \mathrm{mM} \mathrm{NaCl}$. Therefore, these observations suggest that $\mathrm{NaCl}$ is not required for $\mathrm{Tg}$-AGOG to cleave GO-containing DNA.

\section{Substrate specificity of $\mathbf{T g}$-AGOG}

Employing various DNA substrates containing a G/T mismatch, U:G, GO:N (N is $\mathrm{A}, \mathrm{T}, \mathrm{C}$ or $\mathrm{G}), \mathrm{AP}$ and $\mathrm{AP}: \mathrm{N}$ in the cleavage reactions, we examined the substrate specificity of $T g$-AGOG. As shown in Fig. 3C, Tg-AGOG was inactive to mismatched DNA (G/T) and uracil-containing DNA (U/G). By contrast, the enzyme can effectively cleave GO-containing DNA (Fig. 3A), suggesting that the enzyme is a specific glycosylase that works on GO-containing DNA. Furthermore, we observed that $\mathrm{Tg}$-AGOG displayed the highest efficiency for the substrate GO:C, and then followed by the GO:A, GO:T and GO:G, which is consistent with the previous report (Barbier et al. 2016). Thus, $\mathrm{Tg}$-AGOG is specific for GO recognition and removal, rather than the removal of mismatch and other damaged bases.

As mentioned above, $\mathrm{Tg}$-AGOG possesses GO glycosylase and AP lyase activities. To determine whether $T g$-AGOG has an unique AP lyase activity, we employed AP-containing ssDNA and dsDNA as the substrates to investigate the enzyme activity. No cleaved product of $T g$-AGOG was observed when using the AP- 
containing ssDNA and dsDNA as the substrates (Fig. 3B), suggesting that the AP lyase activity of the enzyme requires its GO glycosylase activity.

\section{Mutational studies of $\mathrm{Tg}$-AGOG}

The crystal structure of $\mathrm{Pa}$-AGOG provides insight into clarifying the catalytic mechanism of the enzyme (Lingaraju et al. 2005). The amino acid residues of $\mathrm{Pa}$ AGOG that are involved in GO recognition and removal are shown in Fig. 4A. The sequence alignment shows that $\mathrm{Tg}$-AGOG possess all the amino acid residues that interact with GO. Currently, Pa-AGOG residues F144, P170 and R174 have been proposed to participate in GO binding and GO cleavage, but their exact role has not been clarified.

To address this question, we engineered mutations at the corresponding position in $\mathrm{Tg}$-AGOG to generate three enzyme mutants with alanine substitutions at positions F167, P193 and R197.

As shown in Fig.4B, the three $T g$-AGOG mutant proteins were overexpressed and purified, following the procedures as described for the wild-type protein. We employed the GO-containing ssDNA as substrates to investigate the cleavage activity of the mutants. We found that the F167A and P193A mutants had generally similar cleavage efficiencies to the wild-type protein (Figs. 5A, 5B and 5C), no matter the enzyme concentrations used. By contrast, the R197A mutant displayed only $12 \%$ cleavage percentage at $200 \mathrm{nM}$ (Fig. 5D). At lower concentrations than $200 \mathrm{nM}$, the R197A mutant exhibited $<10$ cleavage percentage. Thus, the cleavage percentage of the R197A mutant is significantly lower than that of the wild-type protein, suggesting that residue R197 of $\mathrm{Tg}$-AGOG is involved in catalysis. However, the R197A mutant displayed the increased cleavage efficiency $(75 \%)$ in the presence of high enzyme concentrations $(800 \mathrm{nM})$, indicating that other residues of $T g$-AGOG are also needed for catalysis besides the residue R197.

\section{Binding studies of $\mathrm{Tg}$-AGOG and its mutants}

To further probe the GO recognition mechanism of $T g$-AGOG, we investigated the DNA binding of the mutant enzymes by EMSA. As shown in Fig. 6A, almost all 
the free GO-containing ssDNA was bound in the presence of $\geq 2,000 \mathrm{nM}$ wild-type Tg-AGOG. The R197A mutant displayed similar GO-containing ssDNA binding efficiencies with the wild-type protein (Fig. 6D), suggesting that the mutation of R197 to alanine has no effect on binding to GO-containing ssDNA. In contrast, quite surprisingly, the F167A and and P193A mutants exhibited the binding efficiencies higher than the wild-type protein when using $200 \mathrm{nM}, 400 \mathrm{nM}$ and $600 \mathrm{nM}$ enzyme in the binding reactions (Figs. 6B and 6C). The results show that the F167A and P193A mutants might have flexible conformation that is helpful for binding DNA, and the mutation of residue R197 to alanine yields no detectable effect on binding to GOcontaining DNA.

\section{Discussion}

GO DNA glycosylases are ubiquitous in bacteria, eukarya and archaea, being capable of removing GO from DNA. However, few archaeal GO DNA glycosylase has been characterized biochemically so far. Herein, we present for the first time data for biochemical characteristics and mutational studies of an archaeal GO DNA glycosylase from Thermococcus species. Our $\mathrm{Tg}$-AGOG is able to remove GO from DNA at higher temperature than previously reported (Barbier et al. 2016). Indeed, the optimal temperature measured for $\operatorname{Tg}$-AGOG is $85^{\circ} \mathrm{C}$, hence ca. 25 degrees higher than that of the GO DNA glycosylases from A. fulgidus and T. volcanium $\left(60^{\circ} \mathrm{C}\right)$ (Chung et al. 2001; Fujii et al. 2016). Furthermore, Tg-AGOG is a lot more thermostable, retaining activity after heating at $95^{\circ} \mathrm{C}$ for 2 hours. AGOGs display varied $\mathrm{pH}$ requirements for their activities. $\mathrm{Tg}$-AGOG shows maximal activity over a broad $\mathrm{pH}$ range from 7.0 to 8.5 . Similarly, the GO DNA glycosylases from $M$. jannaschii and A. fulgidus have a optimal pH 8.4 (Gogos and Clarke 1999; Chung et al. 2001). The $\mathrm{Tg}$-AGOG activity is inhibited by $\mathrm{NaCl}$, even in the presence of low concentration $(50 \mathrm{mM})$. In contrast, $A$. fulgidus OGG exhibits the optimal activity in the presence of $100 \mathrm{mM} \mathrm{NaCl}$ (Chung et al. 2001). Overall, biochemical characterization of $\mathrm{Tg}$-AGOG in this work provides insight into a potential use of glycosylases as new tools for research and applied biotechnologies laboratories 
(Gogos and Clarke 1999).

$T g$-AGOG can excise GO-containing dsDNA with the preferred substrate for $\mathrm{GO}: \mathrm{C}$, and then followed by $\mathrm{GO}: \mathrm{T}>\mathrm{GO}: \mathrm{A}>\mathrm{GO}: \mathrm{G}$, which is consistent with the previous observation (Barbie et al. 2016). However, A. fulgidus OGG exhibits the substrate specificity in the order: GO:C>GO:G>GO:T>GO:A (Chung et al. 2001). Human OGG1 strongly prefers DNA duplexes containing GO:C pair, followed by GO:T>GO:G>GO:A (Hazra et al. 1998). While GO:A was poorly recognized, the GO paired with T, G, or C is a good substrate for the E. coli Fpg (Boiteux et al. 1990). Interestingly, T. volcanium OGG could excise GO positioned opposite all four bases (Fujii et al. 2016), which is distinct from all the other reported OGGs. Thus, the substrate specificity of GO glycosylases from organisms varies. Similar to $T$. volcanium OGG (Fujii et al. 2016), Tg-AGOG cannot eliminate $\mathrm{U}$ from U/G or $\mathrm{T}$ from $\mathrm{T} / \mathrm{G}$. In addition, $\mathrm{Tg}$-AGOG is inactive to AP-containing DNA. These observations demonstrate that $\mathrm{Tg}$-AGOG is specific of GO.

Several GO DNA glycosylases from human (hOGG1), yeast (yOGG1), E. coli (Fpg), and $\mathrm{Pa}$-AGOG (Lingaraju et al. 2005; Sartori et al. 2004; Lingaraju et al. 2009), which are some of the better studied members of this superfamily, possess distinct mechanisms for their lyase activities (Nash et al. 1996; Hazra et al. 1998; Boiteux et al. 1990). The GO is first removed by glycosylase activity and then the phosphodiester bond is cleaved by AP lyase activity through a $\beta$-elimination or $\delta$ elimination reaction. While the $E$. coli Fpg protein adopts a $\delta$-elimination reaction to produce a single nucleotide gap flanked by 3 '- and 5'- phosphate termini, hOGG1, yOGG1 and $\mathrm{Pa}$-AGOG cleave the DNA strand at the resulting AP site after GO removal from DNA via $\beta$-elimination. Our data show that $\mathrm{Tg}$-AGOG resembles hOGG1, yOGG1, and $\mathrm{Pa}$-AGOG, employing a $\beta$-elimination reaction to cleave the DNA strand as suggested before (Barbier et al. 2016).

$\mathrm{Pa}$-AGOG is a well-characterized AGOG. Biochemical and structural data on $\mathrm{Pa}$-AGOG provide insights into its GO recognition and removal. Residues W222, W69, K147, D218 and N31 of Pa-AGOG are important for GO recognition, and its 
residues K140 and D172 are involved in removing GO ( Lingaraju et al. 2005; Sartori et al. 2004; Lingaraju et al. 2009). Although T. gammatolerans and P. aerophilum belong to two separate archaeal phyla: crenarcheota and euryarcheota, the above residues participating in $\mathrm{GO}$ recognition and removal in $\mathrm{Pa}$-AGOG are conserved in Tg-AGOG. This implies that $\mathrm{Tg}$-AGOG and $\mathrm{Pa}$-AGOG might be members of the same glycosylase family, despite their low sequence identity (only $25 \%$ ). The crystal structure showed that GO is encircled by residues F144, P170 and R174 of Pa-AGOG (Lingaraju et al. 2005), however, their function remains unknown. Since residues F167, P193 and R197 of Tg-AGOG are analogous to residues F144, P170 and R174 of $\mathrm{Pa}$-AGOG, we characterized F167A, P193A and R197A mutant enzymes to reveal their function. We found that the R197A mutant retains the compromised activity, suggesting that residue R197 of Tg-AGOG is involved in catalysis, and other residues are also essential for the enzyme activity besides residue R197. The mutational studies show that the K140 of $\mathrm{Pa}$-AGOG, corresponding residue K241 of yOGG1 and K249 of hOGG1, are essential for GO removal (Sebera et al. 2017; Guibourt et al. 2000; Girard et al. 1997). In the Pa-AGOG complex structure, residue R174 of Pa-AGOG form a hydrogen bond to the catalytic D172 to maintain the conformation of enzyme. Partial loss of the $\mathrm{Tg}$-AGOG R197A mutant suggest that this mutation disrupts the hydrogen bond between R197 (R174 of Pa-AGOG) and D195 (D172 of Pa-AGOG). In combination, we proposed that residue $\mathrm{K} 163$ of $\mathrm{Tg}$-AGOG, which is analogous to K140 of $\mathrm{Pa}$-AGOG, and residue R197 of $\mathrm{Tg}$-AGOG are key for catalysis.

The crystal structure of $\mathrm{Pa}$-AGOG showed that the aromatic rings of residues F144 and W222 of the enzyme seem to stimulate the GO to be stacked (Fig. 4). Our data show that F167A of $\mathrm{Tg}$-AGOG leads to much increased binding, although the stack between F167 (F144 of Pa-AGOG), GO and W233 (W222 of Pa-AGOG) is destroyed. On the other hand, P170 of Pa-AGOG might contact GO from the view of the crystal structure, however, its function remains unknown. Similar to F167A mutant, the Tg-AGOG P193A mutant also displays increased binding, suggesting that F167 and P193 might be flexible for enzyme conformation. 
In summary, we characterized biochemically the GO DNA glycosylase from the hyperthermophilic and radioresistant euryarchaeon T. gammatolerans and probed the function of three residues of the enzyme. As expected, $\mathrm{Tg}$-AGOG is a thermostable glycosylase, which has the optimal temperature of $85^{\circ} \mathrm{C}$ for its activity and retains the compromised activity after heated $95^{\circ} \mathrm{C}$ for 2 hours. The enzyme cleaves GOcontaining DNA over a wide $\mathrm{pH}$ spectrum ranging from 6.5 to 9.5 with an optimal $\mathrm{pH}$ of 7.0-8.5. Furthermore, the enzyme is independent on a divalent metal ion for its activity, but is inhibited by $\mathrm{Co}^{2+}, \mathrm{Cu}^{2+}$, and $\mathrm{NaCl}$. The enzyme prefers the duplex substrates in the order: $\mathrm{GO}: \mathrm{C}>\mathrm{GO}: \mathrm{T}>\mathrm{GO}: \mathrm{A}>\mathrm{GO}: \mathrm{G}$. Mutational studies suggest that residue R197 is involved in catalysis.

\section{Acknowledgements}

We thank Prof. Fabrice Confalonieri at University of Paris-Sud for providing the genomic DNA of T. gammatolerans. This work was supported by the Academic Leader of Middle and Young People of Yangzhou University Grant and State Key Laboratory of Microbial Metabolism, Shanghai Jiao Tong University (No. MMLKF18-05) to L.Z.; the practice innovation training program for Postgraudate students in Yangzhou University to H.S (No. 201711117059Y).

\section{Conflict of interest}

All authors declare that they have no conflict of interest.

\section{Ethical Statement}

This article does not contain any studies with human participants or animals performed by any of the authors.

\section{Author contributions}

LZ and ZY designed experiments; YL, HS and DZ performed experiments; LZ, ZY, PO and JZ analyzed data; LZ, ZY, PO and JZ wrote and revised the paper. 


\section{References}

Barbier E, Lagorce A, Hachemi A, Dutertre M, Gorlas A, Morand L, Saint-Pierre C, Ravanat JL, Douki T, Armengaud J, Gasparutto D, Confalonieri F, Breton J (2016) Oxidative DNA damage and repair in the radioresistant archaeon Thermococcus gammatolerans. Chem Res Toxicol 29: 1796-1809

Boiteux S, O'Connor TR, Lederer F, Gouyette A, Laval J (1990) Homogeneous Escherichia coli FPG protein. A DNA glycosylase which excises imidazole ringopened purines and nicks DNA at apurinic/apyrimidinic sites. J Biol Chem 265: 39163922

Bruner SD, Norman DP, Verdine GL (2000) Structural basis for recognition and repair of the endogenous mutagen 8-oxoguanine in DNA. Nature 403: 859-866

Chung JH, Suh MJ, Park YI, Tainer JA, Han YS (2001) Repair activities of 8oxoguanine DNA glycosylase from Archaeoglobus fulgidus. a hyperthermophilic archaeon, Mutat Res 486: 99-111

Faucher F, Doublie S, Jia Z (2012) 8-oxoguanine DNA glycosylases: one lesion, three subfamilies. Int J Mol Sci 13: 6711-6729

Faucher F, Duclos S, Bandaru V, Wallace SS, Doublie S (2009) Crystal structures of two archaeal 8-oxoguanine DNA glycosylases provide structural insight into guanine/ 8-oxoguanine distinction. Structure 17: 703-712

Faucher F, Robey-Bond SM, Wallace SS, Doublie S (2009) Structural characterization of Clostridium acetobutylicum 8-oxoguanine DNA glycosylase in its apo form and in complex with 8-oxodeoxyguanosine. J Mol Biol 387: 669-679

Faucher F, Wallace SS, Doublie S (2010) The C-terminal lysine of Ogg2 DNA glycosylases is a major molecular determinant for guanine/8-oxoguanine distinction. $\mathrm{J}$ Mol Biol 397: 46-56

Fromme JC, Verdine GL (2003) DNA lesion recognition by the bacterial repair enzyme MutM. J Biol Chem 278: 51543-51548

Fujii M, Hata C, Ukita M, Fukushima C, Matsuura C, Kawashima-Ohya Y, Tomobe K, Kawashima T (2016) Characterization of a thermostable 8-oxoguanine DNA glycosylase specific for $\mathrm{GO} / \mathrm{N}$ mismatches from the thermoacidophilic Archaeon 
Thermoplasma volcanium. Archaea 6: 8734894

Girard PM, Guibourt N, Boiteux S (1997) The Ogg1 protein of Saccharomyces cerevisiae: a 7,8-dihydro-8-oxoguanine DNA glycosylase/AP lyase whose lysine 241 is a critical residue for catalytic activity. Nucleic Acids Res 25: 3204-3211

Gogos A, Clarke ND (1999) Characterization of an 8-oxoguanine DNA glycosylase from Methanococcus jannaschii. J Biol Chem 274: 30447-30450

Grollman AP, Moriya M (1993) Mutagenesis by 8-oxoguanine: an enemy within. Trends Genet 9: 246-249

Guibourt N, Castaing B, Van Der Kemp PA, Boiteux S (2000) Catalytic and DNA binding properties of the ogg1 protein of Saccharomyces cerevisiae: comparison between the wild type and the K241R and K241Q active-site mutant proteins. Biochemistry 39: 1716-1724

Harman D (1992) Role of free radicals in aging and disease. Ann N Y Acad Sci 673: $126-141$

Hazra TK, Hill JW, Izumi T, Mitra S (2001) Multiple DNA glycosylases for repair of 8-oxoguanine and their potential in vivo functions. Prog Nucleic Acid Res Mol Biol 68: 193-205

Hazra TK, Izumi T, Maidt L, Floyd RA, Mitra S (1998) The presence of two distinct 8-oxoguanine repair enzymes in human cells: their potential complementary roles in preventing mutation. Nucleic Acids Res 26: 5116-5122

Im EK, Hong CH, Back JH, Han YS, Chung JH (2005) Functional identification of an 8-oxoguanine specific endonuclease from Thermotoga maritima. J Biochem Mol Biol 38: $676-682$

Jolivet E, L'Haridon S, Corre E, Forterre P, Prieur D (2003) Thermococcus gammatolerans sp nov., a hyperthermophilic archaeon from a deep-sea hydrothermal vent that resists ionizing radiation. Int J Syst Evol Microbiol 53: 847-851

Kuchino Y, Mori F, Kasai H, Inoue H, Iwai S, Miura K, Ohtsuka E, Nishimura S (1987) Misreading of DNA templates containing 8-hydroxydeoxyguanosine at the modified base and at adjacent residues. Nature 327: 77-79

Lingaraju GM, Prota AE, Winkler FK (2009) Mutational studies of Pa-AGOG DNA 
glycosylase from the hyperthermophilic crenarchaeon Pyrobaculum aerophilum. DNA Repair (Amst) 8: 857-864

Lingaraju GM, Sartori AA, Kostrewa D, Prota A.E, Jiricny J, Winkler FK (2005) A DNA glycosylase from Pyrobaculum aerophilum with an 8-oxoguanine binding mode and a noncanonical helix-hairpin-helix structure. Structure 13: 87-98

McCullough AK, Dodson ML, Lloyd RS (1999) Initiation of base excision repair: glycosylase mechanisms and structures. Annu Rev Biochem 68: 255-285

Nash HM, Bruner SD, Scharer OD, Kawate T, Addona TA, Spooner E, Lane WS, Verdine GL (1996) Cloning of a yeast 8-oxoguanine DNA glycosylase reveals the existence of a base-excision DNA-repair protein superfamily. Curr Biol 6: 968-980 Park EM, Shigenaga MK, Degan P, Korn TS, Kitzler JW, Wehr CM, Kolachana P, Ames BN (1992) Assay of excised oxidative DNA lesions: isolation of 8-oxoguanine and its nucleoside derivatives from biological fluids with a monoclonal antibody column. Proc Natl Acad Sci U S A 89: 3375-3379

Pearson CG, Shikazono N, Thacker J, O'Neill P (2004) Enhanced mutagenic potential of 8-oxo-7,8-dihydroguanine when present within a clustered DNA damage site. Nucleic Acids Res 32: 263-270

Radom CT, Banerjee A, Verdine GL (2007) Structural characterization of human 8oxoguanine DNA glycosylase variants bearing active site mutations. J Biol Chem 282: $9182-9194$

Sartori AA, Lingaraju GM, Hunziker P, Winkler FK, Jiricny J (2004) Pa-AGOG, the founding member of a new family of archaeal 8-oxoguanine DNA-glycosylases. Nucleic Acids Res 32: 6531-6539

Sebera J, Hattori Y, Sato D, Reha D, Nencka R, Kohno T, Kojima C, Tanaka Y, Sychrovsky V (2017) The mechanism of the glycosylase reaction with hOGG1 baseexcision repair enzyme: concerted effect of Lys249 and Asp268 during excision of 8oxoguanine. Nucleic Acids Res 45: 5231-5242

Seeberg E, Eide L, Bjoras M (1995) The base excision repair pathway. Trends Biochem Sci 20: 391-397

Shibutani S, Takeshita M, Grollman AP (1991) Insertion of specific bases during 
DNA synthesis past the oxidation-damaged base 8-oxodG. Nature 349: 431-434

Shimizu M, Gruz P, Kamiya H, Kim SR, Pisani FM, Masutani C, Kanke Y, Harashima H, Hanaoka F, Nohmi T (2003) Erroneous incorporation of oxidized DNA precursors by Y-family DNA polymerases. EMBO Rep 4: 269-273

Shinmura K, Kasai H, Sasaki A, Sugimura H, Yokota J (1997) 8-hydroxyguanine (7,8-dihydro-8-oxoguanine) DNA glycosylase and AP lyase activities of hOGG1 protein and their substrate specificity. Mutat Res 385: 75-82

Sliwinska A, Kwiatkowski D, Czarny P, Toma M, Wigner P, Drzewoski J, Fabianowska-Majewska K, Szemraj J, Maes M, Galecki P, Sliwinski T (2016) The levels of 7,8-dihydrodeoxyguanosine (8-oxoG) and 8-oxoguanine DNA glycosylase 1 (OGG1) - A potential diagnostic biomarkers of Alzheimer's disease. J Neurol Sci 368: $155-159$

Thayer MM, Ahern H, Xing D, Cunningham RP, Tainer JA (1995) Novel DNA binding motifs in the DNA repair enzyme endonuclease III crystal structure. EMBO J 14: $4108-4120$

Zivanovic Y, Armengaud J, Lagorce A, Leplat C, Guerin P, Dutertre M, Anthouard V, Forterre P, Wincker P, Confalonieri F (2009) Genome analysis and genome-wide proteomics of Thermococcus gammatolerans, the most radioresistant organism known amongst the Archaea. Genome Biol 10 


\section{Figure legends}

Fig. 1. T. gammatolerans encodes an archaeal GO DNA glycosylase (Tg-AGOG). A. the sequence comparison of $\mathrm{Tg}$-AGOG and $\mathrm{Pa}$-AGOG. * represents the amino acid residues that contact $\mathrm{GO}$ by $\mathrm{Pa}-\mathrm{AGOG}$; B. overexpression and purification of $\mathrm{Tg}$ AGOG; C. GO-containing ssDNA and dsDNA cleavage of Tg-AGOG. The GOcontaining ssDNA and dsDNA $(500 \mathrm{nM})$ were used as substrates to determine $T g$ AGOG activity in the presence of $800 \mathrm{nM}$; D. $\mathrm{Tg}$-AGOG is a bifunctional enzyme that possesses GO glycosylase and AP lyase activities. The cleaved product of the enzyme was estimated to be 25 mer. M: marker ( 26 mer, 24 mer and 22 mer).

Fig. 2. Biochemical characterization of $T g$-AGOG. A. the optimal temperature for GO-containing ssDNA cleavage by the enzyme; B. the thermostability of the enzyme; C. the optimal $\mathrm{pH}$ for GO-containing ssDNA cleavage by the enzyme; D. the optimal divalent cations for GO-containing ssDNA cleavage by the enzyme; E. the effect of $\mathrm{NaCl}$ on GO-containing ssDNA cleavage by the enzyme. $\mathrm{CK}$ : the reaction without the enzyme. CK1: the reaction with the enzyme

Fig. 3. Substrate specificity of $T g$-AGOG. The cleavage reactions were performed by $\mathrm{Tg}$-AGOG in the presence of GO-containing dsDNA (GO:C, GO:T, GO:A and GO:G), uracil-containing dsDNA (U:G), mismatch DNA (G:T), AP-containing ssDNA and AP-containing dsDNA (AP:C, AP:T; AP:G and AP:A). A. GO-containing dsDNA cleavage; B. AP-containing DNA cleavage; C. U/G-, G/T- and A/T-containing dsDNA cleavage. CK: the reaction without the enzyme.

Fig. 4. Amino acid residues of Tg-AGOG that could interact with GO. A. The GO binding pocket of $\mathrm{Pa}$-AGOG. The figure was adapted from (Lingaraju et al. 2005). GO is labeled with dots. The corresponding amino acids of $\mathrm{Tg}$-AGOG are shown in the parentless. B. Purification the F167A, P193A and R197A Tg-AGOG mutants.

Fig. 5. The wild-type and mutant Tg-AGOGs cleave GO-containing DNA. $200 \mathrm{nM}$ GO-containing ssDNA was used as the substrate to determine the wild-type and mutant $\mathrm{Tg}$-AGOG activities at $85^{\circ} \mathrm{C}$ for $10 \mathrm{~min}$. Reaction products were detected by 
electrophoresis. A. the wild-type protein; B. the F167A mutant; C. the P193A mutant; D. the R197A mutant. CK: the reaction without the enzyme.

Fig. 6. The wild-type and mutant Tg-AGOGs bind to GO-containing DNA. The GOcontaining ssDNA was incubated with the wild-type and mutant $\mathrm{Tg}$-AGOGs at $25^{\circ} \mathrm{C}$ for $10 \mathrm{~min}$. The bound product was run by electrophoresis. A. the wild-type protein; B. the F167A mutant; C. the P193A mutant; D. the R197A mutant. CK: the binding assay without the enzyme. 
Table 1 Oligonucleotides used in this study.

\begin{tabular}{|c|c|}
\hline Name & Sequence $\left(5^{\prime}-3^{\prime}\right)$ \\
\hline$T g$-AGOG F & GGGAATTCCATATGACGCTCGACCGCTTCGTGAGA \\
\hline$T g-A G O G$ R & AAGGAAAAAAGCGGCCGCGAGATCCCTAAGCTCCAGTAT \\
\hline F167A F & AGCGCGAAAACGATAGTCGCCGCCGTAAAGATGTTC \\
\hline F167A R & GGCGACTATCGTTTTCGCGCTCCTTTTAGCCTTCAT \\
\hline P193A F & CCGATGGCCATCGAGATTGCGGACGATGTGAGAATA \\
\hline P193A R & CGCAATCTCGATGGCCATCGGGTAGGGGACGAAGGC \\
\hline R197A F & GAGATTCCGGACGATGTGGCAATAAACGCCTACACC \\
\hline R197A R & TGCCACATCGTCCGGAATCTCGATGGCCATCGGGTA \\
\hline $\mathrm{p} 45$ & 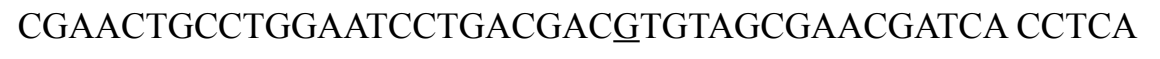 \\
\hline $\mathrm{p} 45 \mathrm{U}$ & CGAACTGCCTGGAATCCTGACGAC倘GTAGCGAACGATCA CCTCA \\
\hline $\mathrm{p} 45 \mathrm{GO}$ & CGAACTGCCTGGAATCCTGACGACGOTGTAGCGAACGATCA CCTCA \\
\hline p45 AP & CGAACTGCCTGGAATCCTGACGACAPTGTAGCGAACGATCA CCTCA \\
\hline $\mathrm{t} 45 \mathrm{C}$ & TGAGGTGATCGTTCGCTACACGTCGTCAGGATTCCAGGCGTTCG \\
\hline $\mathrm{t} 45 \mathrm{G}$ & TGAGGTGATCGTTCGCTACAGGTCGTCAGGATTCCAGGCGTTCG \\
\hline $\mathrm{t} 45 \mathrm{~A}$ & TGAGGTGATCGTTCGCTACAAGTCGTCAGGATTCCAGGCGTTCG \\
\hline $\mathrm{t} 45 \mathrm{~T}$ & TGAGGTGATCGTTCGCTACATGTCGTCAGGATTCCAGGCGTTCG \\
\hline p26 & CGAACTGCCTGGAATCCTGACGACGT \\
\hline p24 & CGAACTGCCTGGAATCCTGACGAC \\
\hline $\mathrm{p} 22$ & CGAACTGCCTGGAATCCTGACG \\
\hline
\end{tabular}

The underlined nucleotides are restriction sites.

The italic nucleotides represent the mutagenic base.

U: uracil; GO: 8oxoG; AP: apurinic/apyrimidinic site. 


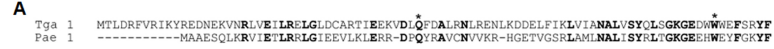

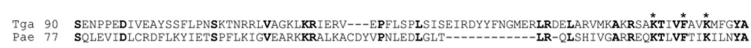

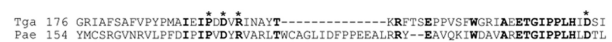

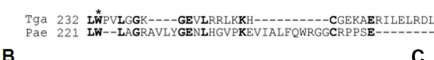

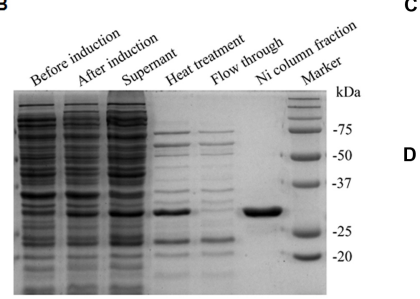

C.

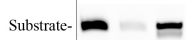

$\begin{array}{lll} & - & \\ \text { Cleavage }(\%) & 89 & 91\end{array}$

Tg-AGOG M +

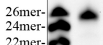




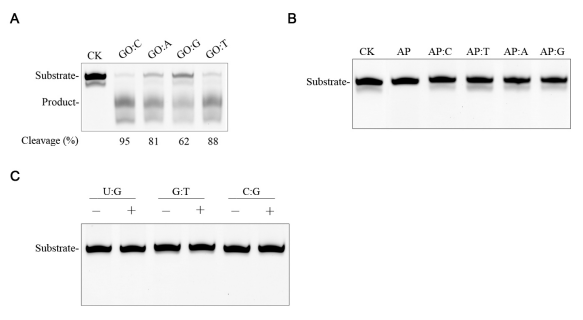


A

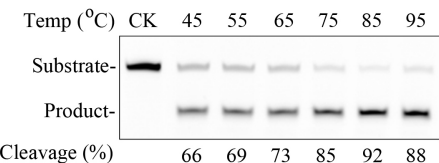

C

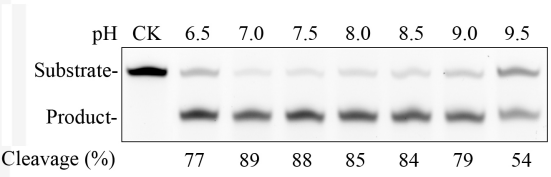

E

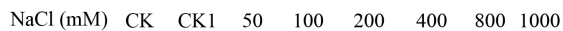

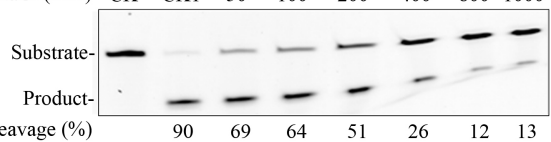

B

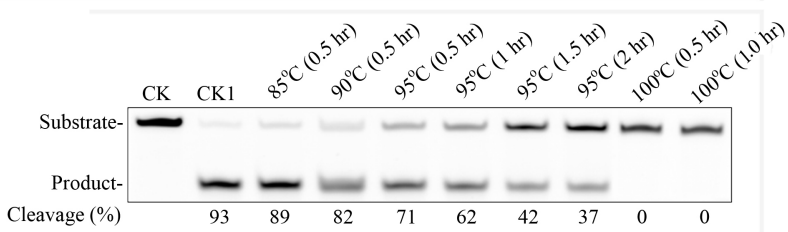

D

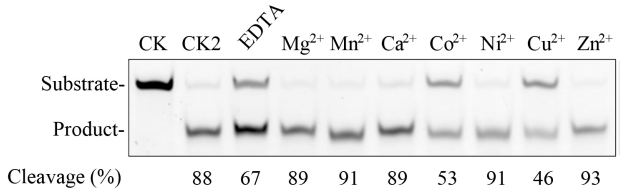



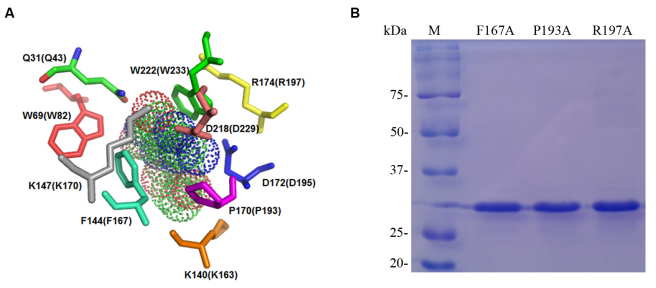


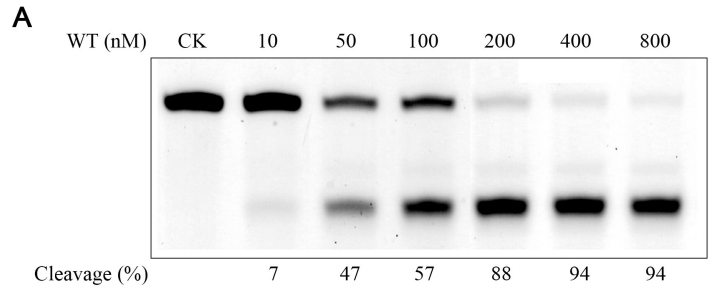

B

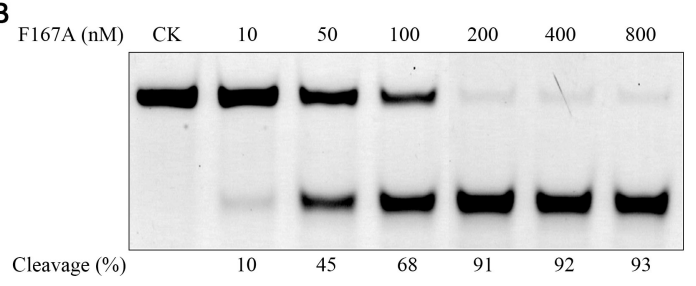

C

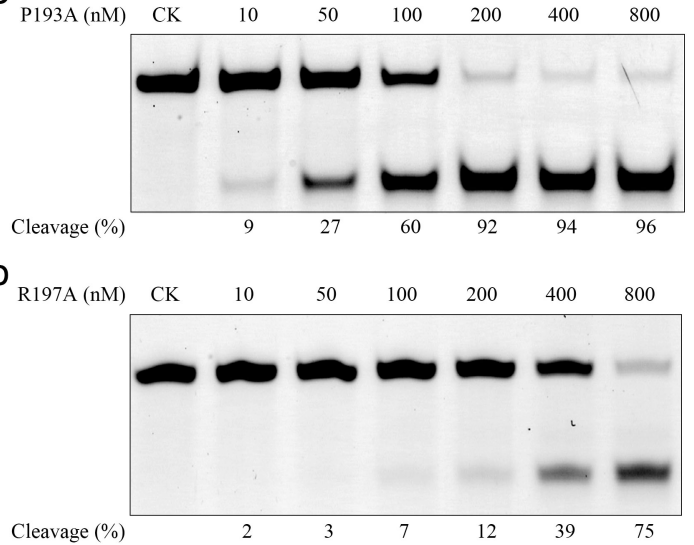


A

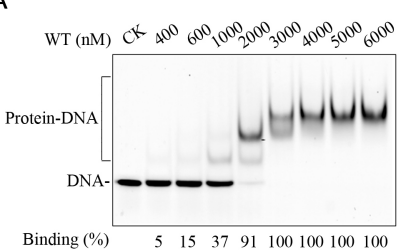

C

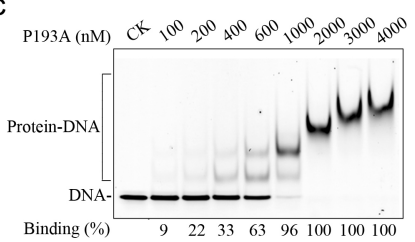

B

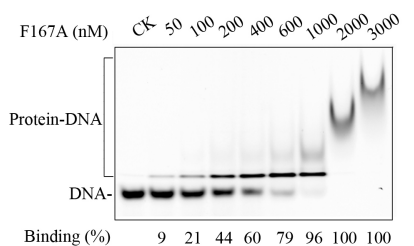

D

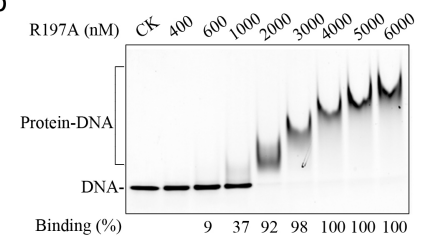

